\title{
Student talk and opportunities for mathematical learning in small group interactions ${ }^{\text {th }}$
}

\author{
Marcy B. Wood*, Crystal A. Kalinec \\ University of Arizona, Tucson, AZ, United States
}

\section{A R T I C L E I N F O}

\section{Article history:}

Received 29 August 2011

Received in revised form 19 December 2011

Accepted 19 December 2011

Available online 10 January 2012

\section{Keywords:}

Identity

Mathematical learning

Group interactions

On task talk

Mathematizing

\section{Introduction}

Over the last several decades, mathematics education researchers have probed multiple features of student talk and arrived at a general consensus that students learn more as they interact with each other. However, not just any interaction will do: Researchers have identified several features conducive to productive talk. Webb and Mastergeorge (2003) described effective help seeking and help giving behaviors, noting the importance of precision and persistence on the part of the help seeker and explanations and monitoring from the help giver. Cobb (in Sfard, Nesher, Streefland, Cobb, \& Mason, 1998) suggested that the focus of mathematical talk was important, noting that talk about mathematical concepts supported learning in ways that talk strictly about mathematical procedures might not. As a final example, Cohen (1994b) summarized the findings of several studies in which student talk was directly correlated to student achievement as long as students worked on tasks that required them to rely on each other.

While this extensive body of research helps us think about the most productive features of student talk, most studies on student talk tend to emphasize what students do as they are on task. However, students are rarely focused on mathematical content for the entire portion of their small group time. Indeed, considering our current preoccupation with accountability and the fact that student engagement (or time on-task) is frequently used as a measure of teacher effectiveness, the time

\footnotetext{
This paper was accepted by the prior Editor-in-Chief, Karen Littleton.

* Corresponding author. Tel.: +1 5206211700.

E-mail address: mbwood@email.arizona.edu (M.B. Wood).
} 
students spend off-task is, these days, teachers' constant worry. In spite of this emphasis, very few researchers have considered off-task behavior. One exception is a study by Joanna Thornborrow (2003). This study suggests that off-task talk provides information about student social interactions and structures that may be helpful in making sense of what happens during on-task talk.

Thornborrow is not alone in her focus on social aspects of learning. Other sociocultural researchers (Andriessen, Baker, \& van der Puil, 2011; Lemke, 1990; Wortham, 2006) argue that because academic learning is a social construct, it inherently contains both academic and social aspects. These researchers suggest that we need to attend to nonacademic aspects of student interactions in order to make sense of their potential contribution to academic learning. Borrowing from these researchers, we suggest that an examination of the types of social and academic interactions students perform while on- and off-task might help explain what motivates or diverts on-task talk, especially academic on-task talk; what initiates and maintains the momentum of off-task talk; and what interactions are more or less conducive to the learning process.

\section{Conceptual framework}

The commognitive framework provides a lens that connects student talk with mathematical learning. As Sfard describes in the introduction to this edition, the commognitive framework defines learning as a change in communication: As students learn mathematics, their mathematical discourse becomes increasingly similar to desirable mathematical discourses. This definition of learning suggests that actual participation in mathematical discourses - in talk about mathematical objects seems a necessary condition for learning. Furthermore, an opportunity for mathematical learning - an opportunity for a change in mathematical discourse - can only arise if a student is engaged in the activity of mathematizing - in communicating about mathematical objects. The importance of mathematizing to learning suggests that the amount and quality of mathematizing positively correlates with mathematical learning.

However, we do not see mathematizing as a sufficient condition for learning mathematics. Because learning is social, there are times in the classroom when students talk about things other than mathematical objects, and in particular about people (themselves or others). Certain types of this talk may also play an important role in mathematical learning. Talk about people, or subjectifying talk, may sometimes focus on what people are doing or are supposed to so. For example, one student may tell another to be quiet or may ask another for help on a problem. Another student may engage in talk about her own problem solving activity in an attempt to control it and decide about further steps. These utterances about doing will be called action-oriented subjectifying (AOS). Another category of subjectifying talk consists of utterances about being or having. This latter type of talk will be called identifying (note that these utterances can also be called identity-oriented subjectifying). Identifying utterances focus on who a person is or what a person has, that is, talk about a person's features, attributes, and/or possessions. Identifying utterances include students' talk about themselves as dumb, about others as smart, or about having gold teeth or a fat head.

Because subjectifying utterances of both types are not specifically about mathematical objects, they do not directly contribute to mathematical learning. However, subjectifying utterances may play an important role in promoting or inhibiting learning, depending upon the opportunities they provide for students to engage in mathematical talk. Subjectifying discourse may limit mathematical talk when it displaces this latter talk or suggests that students should not engage in it. For example, the adage, "ours is not to reason why, just invert and multiply" limits mathematical learning because it focuses the learner on performing an operation, rather than on reasoning, or talking about, mathematics. However, subjectifying talk may support mathematical learning when it focuses students on mathematical content, facilitates group dynamics, or encourages students' positive identification with mathematics. For example, when a student reminds off-task students that they need to focus on their work, she might facilitate learning by inducing more mathematical talk.

Although this study partitions talk into mathematizing and subjectifying, we do not mean to imply that investigation of talk about mathematical objects should be removed from talk about people and their activity. A fundamental premise of the commognitive framework is that social and cognitive aspects of mathematical learning are inherently intertwined. They are often two different sides of the same coin - two aspects of the same utterances. Yet, in spite of this intimate interconnection, we contend that it is still possible and even productive to distinguish and separately reflect upon mathematizing talk and subjectifying talk. This separate focus allows greater insight into the contribution of each component. Still, it is the integration between the different aspects of classroom talk that is the special contribution of this paper: It addresses cognitive, interpersonal, and intrapersonal issues in one study and treats them as intimately interconnected. As a consequence, this study provides insights about the process of mathematical learning only available when we consider these issues together.

For this reason, in our analyses, we considered the entirety of small group interactions, examining on-task and off-task interactions. Our purpose was to identify the types of interactions in which students engage and explore the relationship between those interactions and mathematical learning.

We specifically pursued three research questions:

- What were the frequency, range, and patterns of interactions in which students engage as they worked on mathematical tasks in small groups?

- How did small-group interactions create or limit opportunities for learning?

- How did they support or hinder student's ability to take advantage of thus created opportunities for learning? 


\section{Method}

This paper analyzes one case of three students interacting during one mathematics lesson. This case comes from a larger study of connections across learning, mathematizing, and identifying in fourth grade students' mathematical discourse (see Wood, 2008). The larger study consisted of 32 videotaped lessons (over $70 \mathrm{~h}$ of classroom video) of students studying mathematics in small groups in one elementary classroom. We selected this case from the larger study because it contained utterances from each of the categories described above, including a particularly wide variety of subjectifying utterances. This diversity provided an opportunity to examine connections across different kinds of utterances as well as connections between kinds of utterances and mathematical learning. This case reflects typical activity during mathematics lessons in this classroom in terms of the mathematical task, the organization of students into groups, and the presence of on- and off-task talk. However, the kinds of off-task talk, including identity-oriented subjectifying utterances, while present in many other instances, were not always present in the same way or to the same degree as in this case.

The class featured in the larger study was not typical of the school: teachers in the school described the students in this class as difficult. The children were separated from other classes during recess and lunch times, and had a history of substitute teachers who quit because, to use the principal's words, the students were "emotionally challenging." The teacher in this lesson, whom we shall call Mrs. Smyer, relocated to this classroom from another classroom in the school one month before this lesson. The principal and the teacher hoped that placing a regular teacher from the school in the classroom would provide the stability and structure to improve the social and academic environment of this classroom. This was a reasonable assumption: The class started the year without any particular problems or behavioral labels. The students were regular education students drawn from across the fourth grade cohort in the school. However, as the year progressed, the students gained notoriety for their behavior. Mrs. Smyer agreed to move into the class because she felt that the students were good students who could, with the right teacher, make better choices.

While the behavior of students in this classroom was described as atypical, the demographics of the students reflected the population of the school. The elementary school included grades kindergarten through fifth. It was located in a residential area of a midsize Midwestern city. This fourth grade classroom had 20 students, 7 boys and 13 girls, between the ages of 9 and11 years old. Eleven students identified as Black. Seven students identified as White. One student identified as Asian and one student identified as Hispanic. None of the students were labeled as English language learners. Twelve students received free or reduced rate lunches. The teacher, Mrs. Smyer, was White, had 15 years of teaching experience, and had been recognized by the district as the outstanding elementary teacher of the year. During mathematics lessons, Mrs. Smyer typically organized the students into groups and required them to work together on a task. This instructional strategy was a significant shift for the students whose former teachers had emphasized independent work on mathematical tasks.

This case focuses on a group of three students: Rebecca, a White girl, and two Black boys, Jakeel and Daren (see Fig. 1). Rebecca and Daren were regular partners. However, on the day of this lesson, the third member of their group, Nerissa, was not in school. Jakeel was taking her place in the group at the request of the teacher. While these students knew each other and had at times worked with each other, they had not yet worked together as a group of three on mathematics lessons. Also, at the time of

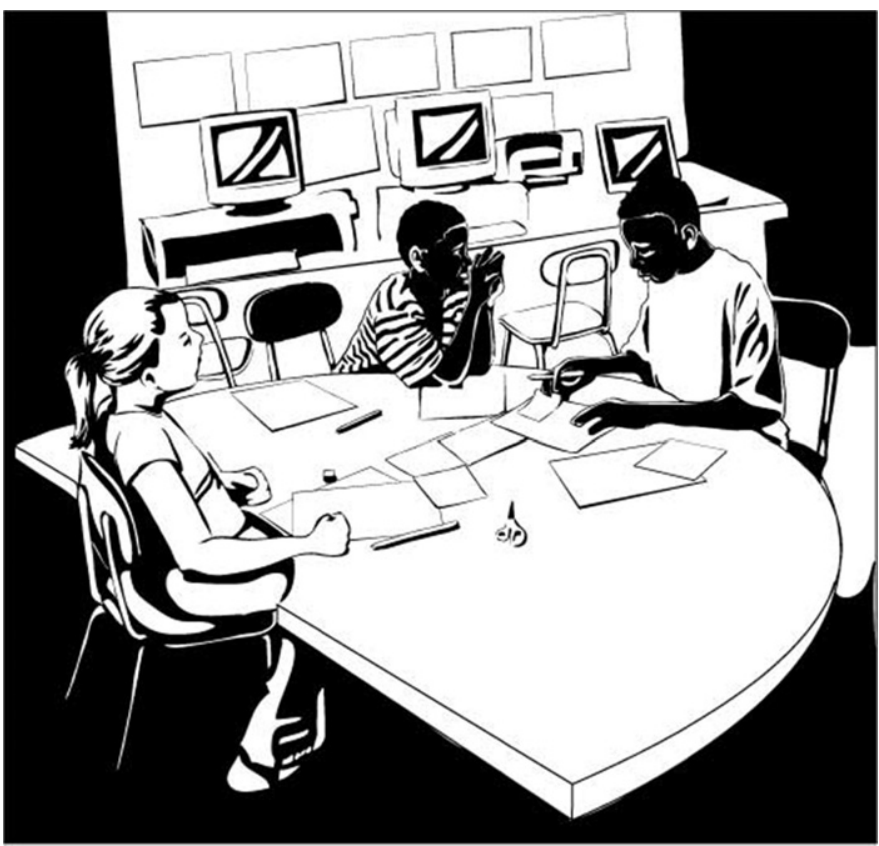

Fig. 1. From left to right, Rebecca, Daren, and Jakeel working on the task 


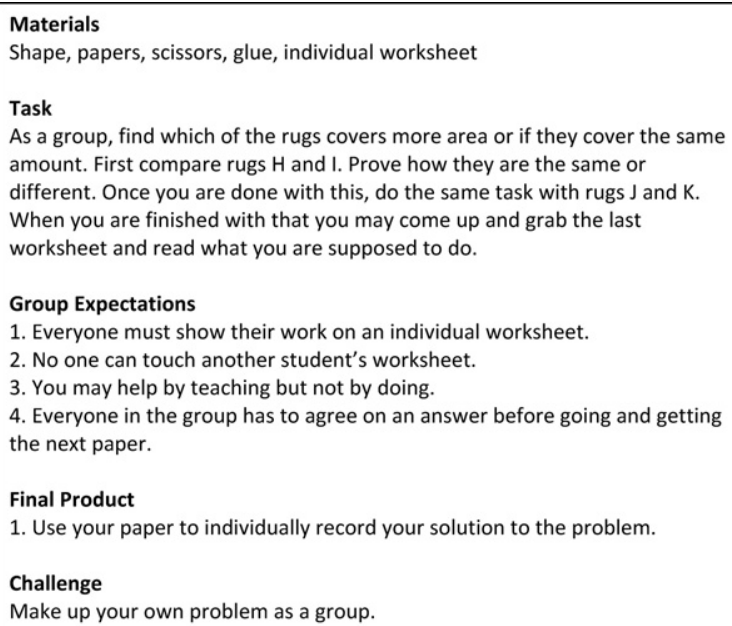

Fig. 2. Reproduction of the task card for this lesson.

this lesson, Mrs. Smyer had been in this classroom for four weeks. Although she consistently used groupwork during this time (sometimes several times during the day), the students were still adjusting to the norms of working together.

Jakeel was well-known by teachers in the school as a "likeable" kid who frequently got into trouble for his behavior. As the following quote from the school principal illustrates, Jakeel was also perceived as an unsuccessful student: "I think there is something not quite connecting with him.... He struggles.... He doesn't just give up, but he really doesn't even know the questions to ask sometimes. He's just stuck and he doesn't know what he doesn't know." In contrast, Jakeel described himself as "really smart" in math - explicitly stating this during an interview and in class. This contrast between Jakeel's identification of himself and that of the adults in the school made him a particularly interesting student. As a consequence, he was one of four focal students for the larger study (Wood, 2008).

Rebecca and Daren were much less notorious across the school than Jakeel. They were not topics of conversation in the teachers' lounge nor were they warned to behave themselves prior to assemblies (as was Jakeel). Daren was seen as a quiet student who, according to another student, was a good person to work with on projects because he was easy to get along with. Rebecca was seen as smart by both the teacher and the other students although, according to the teacher, she would rather be seen as cool than smart.

The focal lesson for this case was day five of an eight day unit on area. In the days prior to this lesson, the students worked on tasks that involved finding the area and perimeter of a variety of rectangular and triangular shapes. The class had particularly struggled to find the area of triangular shapes, prompting the teacher to design the task in this lesson.

This focal lesson asked students to compare the area of pairs of figures, one triangle and one rectangle, to determine which figure "covered more area." These directions came in the form of a one page task card which listed materials needed, the task, group expectations, and the final product (see Fig. 2). Students were to read the task card to determine their work for the lesson. The students were given two sets of figures to compare, receiving first figures $\mathrm{H}$ and $\mathrm{I}$ and then figures $\mathrm{J}$ and $\mathrm{K}$ (see Figs. 3 and 4).
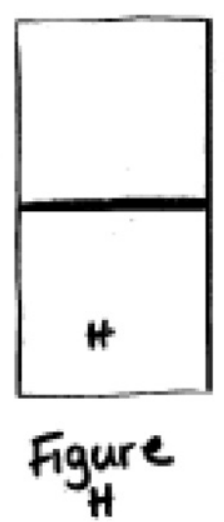
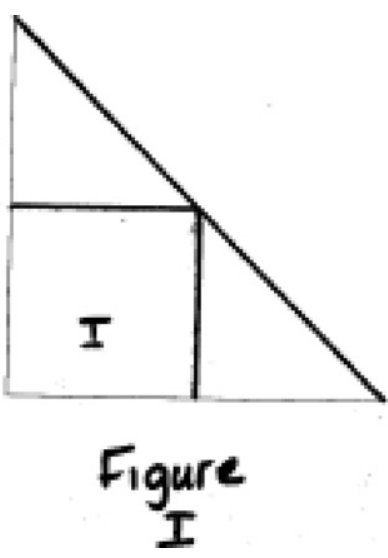

Fig. 3. First pair of figures for this lesson's task. 


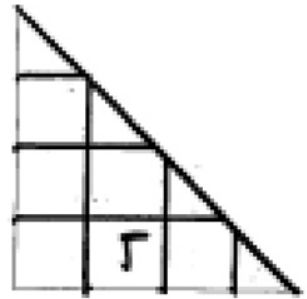

Figure $\mathrm{J}$

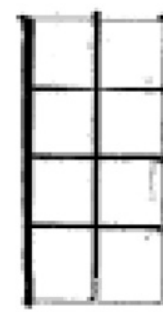

\section{Figure $k$}

Fig. 4. Second pair of figures.

The teacher expected the students to help each other with the task and to agree upon an answer, but she also required that all students produce their own written product, demonstrating their thinking about each answer. Rebecca, Daren, and Jakeel spent 54 min working on this task and were able to arrive at a teacher-approved answer for both pairs of figures by the conclusion of the lesson.

Our data in this paper are transcriptions of the entire videotape. We then divided the transcript into turns based upon who was speaking. We then further divided each speaker's turn into one or more utterances based upon the focus of talk. In the findings below, we present several excerpts of transcripts. The numbers to the left of utterances correspond with the position of the excerpt within the transcript as a whole.

In order to evaluate the different kinds of talk that present in the lesson, we generated categories and coded each line. We started by identifying all mathematizing and all subjectifying utterances, noting subjectifying utterances that were also identifying and noting whether the subjectifying was related to the task or not (for a summary of all codes, see Table 1).

Table 1

List of codes and descriptions.

\begin{tabular}{|c|c|c|c|c|c|c|}
\hline & \multicolumn{3}{|c|}{ Code description } & Code & Description & Example from Transcript \\
\hline \multirow[t]{4}{*}{$\begin{array}{r}\text { On task } \\
\text { codes }\end{array}$} & \multicolumn{3}{|c|}{ Mathematizing } & On $M$ & $\begin{array}{l}\text { Any utterance about a mathematical } \\
\text { object }\end{array}$ & $\begin{array}{l}\text { Daren states, "That's two } \\
\text { squares. So they cover the } \\
\text { same area." (Turn 170) }\end{array}$ \\
\hline & \multirow[t]{2}{*}{ Subjectifying } & \multicolumn{2}{|c|}{$\begin{array}{l}\text { Action-oriented } \\
\text { subjectifying }\end{array}$} & On AOS & $\begin{array}{l}\text { Any utterance that focuses on a } \\
\text { person's on-task actions rather } \\
\text { than on the person as such }\end{array}$ & $\begin{array}{l}\text { Daren states "We gotta ask } \\
\text { before you get up" (Turn } 73 \text { ) }\end{array}$ \\
\hline & & \multicolumn{2}{|l|}{ Identifying } & On I & $\begin{array}{l}\text { Any utterance about who a person } \\
\text { is or his/her features. }\end{array}$ & $\begin{array}{l}\text { The teacher asks "Who's your } \\
\text { materials person" (Turn 754) } \\
\text { and Daren responds with } \\
\text { "Jakeel" (Turn 755). }\end{array}$ \\
\hline & \multicolumn{3}{|c|}{ None of the above } & On $N$ & $\begin{array}{l}\text { Any utterance that was on task, but } \\
\text { did not fall into any of the other } \\
\text { on-task categories. }\end{array}$ & $\begin{array}{l}\text { Rebecca states "Yeah" when } \\
\text { asked if she had the scissors } \\
\text { to complete the task (Turn 208) }\end{array}$ \\
\hline \multirow[t]{5}{*}{$\begin{array}{r}\text { Off task } \\
\text { codes }\end{array}$} & \multirow[t]{4}{*}{ Subjectifying } & \multicolumn{2}{|c|}{$\begin{array}{l}\text { Action-oriented } \\
\text { subjectifying }\end{array}$} & Off AOS & $\begin{array}{l}\text { Any utterance that focuses on a } \\
\text { person's off-task actions rather than } \\
\text { on a person as such. }\end{array}$ & $\begin{array}{l}\text { When asked about soccer, } \\
\text { Rebecca stated "I got hit in } \\
\text { the head with the ball" } \\
\text { (Turn 421). }\end{array}$ \\
\hline & & \multirow[t]{3}{*}{ Identifying } & Identifying & Off $I$ & $\begin{array}{l}\text { Any utterance about who a person is } \\
\text { or his/her features, not including any } \\
\text { utterance coded as blazing or } \\
\text { inappropriate identifying. }\end{array}$ & $\begin{array}{l}\text { Jakeel states "I ain’t stupid, } \\
\text { Rebecca" (Turn 235a) }\end{array}$ \\
\hline & & & Blazing & Off $B$ & $\begin{array}{l}\text { Any utterance that is an exaggerated } \\
\text { negative identification of another } \\
\text { person or members of another's family }\end{array}$ & $\begin{array}{l}\text { Jakeel states "At least my } \\
\text { momma don't got a glue head, } \\
\text { stick head" (Turn 501). }\end{array}$ \\
\hline & & & $\begin{array}{l}\text { Inappropriate } \\
\text { identifying } \\
\text { (e.g. cursing, } \\
\text { swear words) }\end{array}$ & Off $C$ & $\begin{array}{l}\text { Any identifying utterance that uses } \\
\text { words inappropriate for school. }\end{array}$ & $\begin{array}{l}\text { Jakeel states "Bitch, you a ho" } \\
\text { (Turn 472). }\end{array}$ \\
\hline & \multicolumn{3}{|c|}{ None of the above } & Off $N$ & $\begin{array}{l}\text { Any utterance that is off-task and } \\
\text { does not fall into the categories above }\end{array}$ & $\begin{array}{l}\text { Daren states “Camera's on" } \\
\text { (Turn } 82 \text { ). }\end{array}$ \\
\hline Not coded & \multicolumn{3}{|l|}{ Not coded } & $N C$ & Indiscernible utterances & $\begin{array}{l}3 \text { min into the task, the sound } \\
\text { grabber briefly malfunctions and } \\
\text { does not pick up any sound. } \\
\text { (Turns } 48 \text { to } 57 . \text {.) }\end{array}$ \\
\hline
\end{tabular}


As we coded, we added nuances. To count as mathematizing, an utterance had to specifically point at a mathematical object. For example, if the students were making sense of their worksheet by counting the unit blocks in the figures or explaining their strategy of solving the task to another student, we coded it as mathematizing. In contrast, when students spoke about scissors or the size of Jakeel's writing, we determined that the focus of the talk was on non-mathematical objects (scissors and writing size) and we did not include these utterances as mathematizing. We also did not count as mathematizing those utterances that were uttered while students were reading the task or while they read an answer out loud for another student to copy. These latter utterances were coded as on-task subjectifying (see below for more information). Because we were interested in Jakeel's learning, we also further subdivided mathematizing into mathematical talk involving Jakeel (in which Jakeel was an author or an addressee) and talk not involving Jakeel. All mathematizing talk was assumed to be on-task talk.

We divided subjectifying talk into several categories. These utterances were first coded as either on-task or off-task. We decided to code on- and off-task talk because these distinctions were relevant and meaningful to the students and the teacher. These categories recognized and sorted talk into that which was appropriate for the task (on-task) and that which was not (off-task). These categories are value-laden, with off-task talk seen as undesirable and detracting from learning while on-task talk gets credit for any academic advancement. While we recognized these potential judgments, we were purposeful in considering how talk of either kind could potentially advance or undermine mathematizing and learning. For the purposes of this study, any utterance related to the task was considered to be on-task, whether, from the perspective of the teacher, it was desirable or not. For example, negotiations about who gets one color of scissors or another were considered on-task because the students needed scissors in order to accomplish the work of the task. In contrast, Jakeel's talk about pounding the table and making his scissors jump was coded as off-task.

Subjectifying talk (both on and off task) was then parsed into utterances about doing, labeled as action-oriented subjectifying or AOS; and utterances about being or having, labeled as identifying. Talk in which the discursive focus was on the performer(s) of actions rather than on actions or objects was coded as action-oriented. Talk that directly identified others (i.e. you are statements) or described their features was coded as identifying.

In addition to talk that specifically identified individuals (i.e. "You're nasty"), we also specified two variations of identifying talk. We noted when identifying talk used words that could be construed as inappropriate for school. These obscene words included references to sexual orientation, sexual activity, and mental functioning. We also noted when students engaged in what they labeled as "blaze". This talk resembled what Smitherman (2000) described as the dozens or snaps. The students traded negative identifying utterances about either members of each others' families (for example, "At least my momma don't got a skillet head like your momma") or about each other ("Your head is as big as Saturn"). "Blazing" is described in more detail in the findings section.

Two final coding categories were none of the above and not coded. There were instances in which students' utterances were not focused on mathematical objects or on the performers of actions. For example, the students occasionally sang parts of songs or talked about the scissors jumping (as Jakeel pounded on the table). These utterances were coded as none of the above. There were also times in which either the utterance was unintelligible or the focus of the utterance could not be clearly identified. These utterances were labeled as not coded.

While our codes can be grouped into larger categories (e.g. on-task or off-task), each code is mutually exclusive. For example, we used Off-task Identifying (OffI) to label utterances that were off-task and identifying (rather than action-oriented subjectifying) but were not Blazing (Off B) or Inappropriate identifying (Off $C$ ). Thus utterances were not double-coded and each row in Table 1 represents a category that is disjoint from other rows.

Once codes were finalized, both authors separately coded the entire document. These codes were compared and discrepancies were resolved through discussion. After a delay of several months, the first author recoded the entire transcript. Codes from this second pass that did not match the first pass ( $16 \%$ of all codes) were recoded by the second author. A final decision on coding was then made through discussion between the two authors. These codes were then counted. Finally, beginning and ending times were established for each utterance and total time participants spent engaged in each kind of talk was calculated. Because our codes were defined with the help of explicitly specified linguistic markers, we felt confident that they were operational and thus adequate for generating claims. The frequency counts and total time per code allowed us to consider the relative prominence of the different categories of talk. It also supported the generation of several hypotheses regarding the role and interaction of different kinds of student talk.

Along with this quantitative analysis, we also conducted a qualitative analysis of the transcript. As Miles and Huberman (1994) note, use of both quantitative and qualitative data allows a richer exploration of the data than is possible with either alone. While the quantitative data can show generalities, situate specific moments in the whole, and provide additional information about qualitative data, qualitative analysis allows for verification, validation, illustration, and enrichment of the quantitative data. Linkage of quantitative and qualitative data seems especially important in analysis of discourse as quantitative data, with their focus on local units, such as turns, run the risk of obscuring meanings developed across multiple turns or across the lesson.

Our qualitative analysis sought to make sense of student interactions across the lesson and the relationship of different kinds of talk to mathematical learning. The transcript was examined turn by turn to determine possible academic and social functions of each turn with specific attention to the progression of mathematizing, the desirability of mathematical discourse, and how students positioned each other socially and academically. This paper highlights the qualitative data that illustrate different categories of student talk. However, a more detailed description of the sequence of the lesson and more 
Table 2

Type and frequency of utterances during lesson.

\begin{tabular}{|c|c|c|c|c|c|}
\hline & & \multirow[t]{2}{*}{ Code description } & \multirow[t]{2}{*}{ Code } & \multicolumn{2}{|c|}{ Utterances $(N=749)$} \\
\hline & & & & Number & $\%$ \\
\hline \multirow[t]{4}{*}{ On task codes } & Mathematizing & \multirow{4}{*}{$\begin{array}{l}\text { Action-oriented subjectifying } \\
\text { Identifying }\end{array}$} & On $M$ & 79 & $10.6 \%$ \\
\hline & Subjectifying & & On AOS & 213 & $28.4 \%$ \\
\hline & & & On I & 5 & $0.7 \%$ \\
\hline & None of the above & & On $N$ & 39 & $5.2 \%$ \\
\hline \multirow[t]{5}{*}{ Off task codes } & Subjectifying & \multirow{5}{*}{$\begin{array}{l}\text { Action-oriented subjectifying } \\
\text { Identifying } \\
\qquad \begin{array}{l}\text { Identifying } \\
\text { Blazing } \\
\text { Inappropriate identifying } \\
\text { (e.g. cursing, swear words) }\end{array}\end{array}$} & Off AOS & 156 & $20.8 \%$ \\
\hline & & & Off I & 39 & $5.5 \%$ \\
\hline & & & Off $B$ & 84 & $11.2 \%$ \\
\hline & & & Off $C$ & 18 & $2.4 \%$ \\
\hline & None of the above & & Off $N$ & 80 & $10.6 \%$ \\
\hline Not coded & Not coded & & $N C$ & 34 & $4.5 \%$ \\
\hline
\end{tabular}

information about the functions of student talk is available from Wood (2008). Also, the transcript of the lesson is available online at the International Journal of Educational Research website. See the introduction of this special edition for more details.

\section{Findings}

Table 2 summarizes the type and frequency of utterances in the lesson. Figure 5 uses a graphical representation to show Table 2 data. We elaborate each of the categories in Table 1 and Fig. 5 in the sections below. These categories are organized in the order of decreasing number of utterances.

\subsection{Subjectifying}

\subsubsection{Action-oriented subjectifying: talk about doing}

As suggested above, subjectifying talk focuses on people, who they are (identifying talk) and what they are doing (actionoriented subjectifying) rather than on mathematical objects. In this lesson, the majority of task-related utterances (utterances aiming to advance the implementation of the mathematical task at hand) were subjectifying rather than mathematizing. In particular, the subjectifying talk was primarily talk about what the students were or should be doing (action-oriented subjectifying). These on-task action-oriented subjectifying utterances (AOS) totaled 213 utterances or more than half of the total of on-task talk.

Some of this AOS talk supported students in making sense of the task. For example, early in the lesson, Rebecca asked the teacher, "Are you supposed to do the one that covers the least? Like that one paper that we did? It doesn't say that" (Turn 90). Rebecca was unsure whether they were supposed to find the area of the rug that covered the least area. This inquiry about

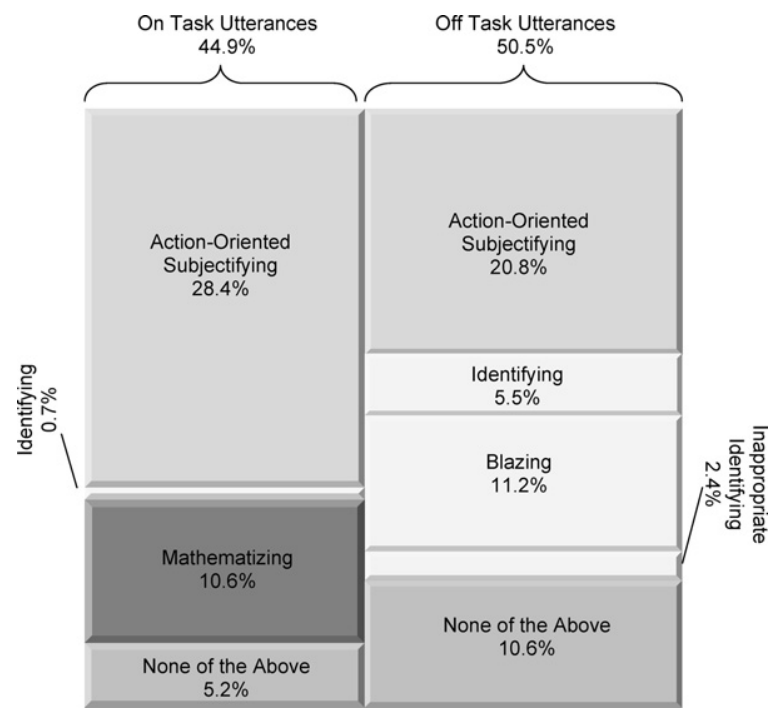

Fig. 5. Findings out of 749 Utterances. 
what the students were to do seemed to contribute to Rebecca's eventual mathematical work as it helped her determine the extent of the task.

In other instances, AOS talk led directly to mathematizing talk. For example, the excerpt below occurred 17 min into the task. The teacher came to the group to check on their work. Jakeel was cutting out figures $\mathrm{H}$ and $\mathrm{I}$.

Excerpt 1. The teacher checks in with Jakeel.

\begin{tabular}{|c|c|c|c|c|}
\hline Turn \# & Speaker & What is Said & What is Done & Code \\
\hline 224 & Teacher & So what are you doing, Jakeel? & & On AOS \\
\hline 225 & Jakeel & I gotta cut these out and $=$ & $\begin{array}{l}\text { He is holding the paper with Figures } H \text { and } I . \text { He points } \\
\text { at it with his scissors. The teacher interrupts him. }\end{array}$ & On AOS \\
\hline 226 & Teacher & Why you gotta cut them out? & & On AOS \\
\hline 227 & Jakeel & $\begin{array}{l}\text { Because I have to make these } \\
\text { two a rectangle just like these three. }\end{array}$ & $\begin{array}{l}\text { He points at his paper with his scissors. His motions } \\
\text { are hidden from the camera by his paper. }\end{array}$ & On $\mathrm{M}$ \\
\hline 228 & Teacher & $\begin{array}{l}\text { Okay. Why are you making } \\
\text { it a rectangle? }\end{array}$ & & On $\mathrm{M}$ \\
\hline 229 & Jakeel & $\begin{array}{l}\text { Because if you don't it won't } \\
\text { cover the whole thing. }\end{array}$ & $\begin{array}{l}\text { Jakeel is looking at the teacher as he talks. It is unclear } \\
\text { what "it" and "the whole thing" are. }\end{array}$ & On $\mathrm{M}$ \\
\hline
\end{tabular}

The teacher's sequence of AOS questions (Turns 224 and 226) resulted in Jakeel's mathematical explanations in Turns 227 and 229. Jakeel might have responded to the teacher's questions in a variety of ways, including ways that did not focus on mathematical objects (For example, he might have said that cutting out the figures was just what he was supposed to do). However, the teacher's focus on explaining his actions ("why" in Turn 226) seemed to open the door to the possibility of mathematizing, an opportunity Jakeel accepted.

However, not all AOS talk lead to mathematizing talk. For example, 27 min into the lesson the following episode of pure action-oriented subjectifying took place. Rebecca had finished her work comparing figures $\mathrm{H}$ and I (see Fig. 3 ), but could not go on to the next problem until everyone in her group had completed their own work on the problem. In this excerpt, we see Rebecca simply telling Jakeel what to do.

Excerpt 2. Rebecca tells Jakeel what to do.

\begin{tabular}{|c|c|c|c|c|}
\hline $349 a$ & Jakeel & What am I supposed to write again? & He talks to Rebecca. & On AOS \\
\hline $349 \mathrm{~b}$ & Rebecca & You're playing & & On AOS \\
\hline $349 c$ & Jakeel & What am I supposed to write? (inaudible: Well you play too much) & & On AOS \\
\hline 350 & Rebecca & They... H and I cover the same amount of floor. & & On AOS \\
\hline 352 & Rebecca & I mean just cover the same amount & Jakeel writes. & On AOS \\
\hline 355 & Rebecca & $\begin{array}{l}\text { H and I cover the same amount of floor. No just they cover the same amount. } \\
\text { Same. Amount. Do you try to write small? All right. That's all you gotta write. }\end{array}$ & $\begin{array}{l}\text { She watches Jakeel write. } \\
\text { Rebecca reads as Jakeel writes. }\end{array}$ & $\begin{array}{l}\text { On AOS } \\
\text { On AOS }\end{array}$ \\
\hline
\end{tabular}

While Rebecca used mathematical words in this excerpt, she was not engaging Jakeel in thinking about mathematical objects nor did she attempt to explain her mathematical thinking (Compare this to her mathematizing talk in Excerpt 18, Turn 609 below). Instead, her words were dictation for Jakeel to record. Unlike the teacher's talk in Excerpt 1, Rebecca's AOS turns did not require or even invite Jakeel to connect the words to mathematical objects.

This example of AOS was typical of Rebecca's interactions with Jakeel and Daren in this lesson. Of the 213 utterances that were on-task AOS, 80 were uttered by Rebecca. Almost half (39) of those 80 utterances specifically addressed Jakeel and/or Daren's physical activity and did not include an invitation to talk about anything, much less about mathematics. Indeed, as noted above, only 15 of the 213 AOS utterances were followed by mathematical talk and 8 of those 15 were initiated by the teacher (as in Excerpt 1). Thus when students engaged in AOS talk (which was the majority of the on-task talk), they provided their peers with very limited opportunities to respond with mathematical talk.

In the course of the lesson, there was an interesting development in Jakeel's participation in this type of subjectifying talk $^{1}$. He initially resisted Rebecca's attempts to tell him what to do. For example, this was what happened after Rebecca told him to copy her work:

Excerpt 3. Jakeel resists Rebecca.

\begin{tabular}{lll}
\hline 213 & Jakeel & $\begin{array}{l}\text { I do not want to write that } \\
\text { I know what= }\end{array}$ \\
\hline
\end{tabular}

\footnotetext{
${ }^{1}$ It might seem surprising that the interactions between Jakeel and Rebecca shifted so much during this lesson. However, this lesson is the first time Jakeel worked with Rebecca on this type of task which might explain why he and Rebecca were still forming the routines of their interactions.
} 
Jakeel continued this resistance at a later moment when Rebecca told him that his answer was wrong and that he would have to rewrite it:

Excerpt 4. Rebecca persists in directing Jakeel.

\begin{tabular}{llll}
\hline 278 & Rebecca & What did you just do, boy? & On AOS \\
279 & Jakeel & I'm looking for the other piece. & On AOS \\
280 & Rebecca & $\begin{array}{l}\text { You wasn't supposed to do that Jakeel. Jakeel. } \\
\text { Jakeel what you was supposed to dooo is do this. }\end{array}$ & $\begin{array}{l}\text { She takes his paper and pushes her paper } \\
\text { toward Jakeel. }\end{array}$ \\
281 & Daren & What we did & He looks at Rebecca's paper. \\
282 & Jakeel & Oh. Oh. & She tries to pull up Jakeel's glued pieces. \\
283 & Rebecca & So you have to take it and rewrite it and & She points at an extra paper. \\
& & I'll cut these out for you. Rewrite what & On AOS \\
284 & Jakeel & I don't want to rewrite. & On AOS \\
285 & Rebecca & Well you have to because you messed up. & Jakeel picks up his pencil and starts writing. \\
& & & Rebecca starts cutting.
\end{tabular}

After this, Jakeel actively asked Rebecca what to do:

Excerpt 5. (Also part of Excerpt 2 above).

349a Jakeel What am I supposed to write again? $\quad$ He talks to Rebecca.

Through persistent use of AOS talk, Rebecca was able to persuade Jakeel that he was not able to do the task on his own and he needed to do as she directed. The turning point in their interactions occurred in Turns 278 to 285 (Excerpt 4) as Rebecca evaluated Jakeel's work. She did not simply tell him what to do, but also told him that what he had done was wrong. That AOS talk, along with Daren's agreement with Rebecca (Turn 281) and Jakeel's examination of Rebecca's work (Turn 282) seemed to convince Jakeel that he could not engage in mathematical talk and that he needed to follow Rebecca's directions.

As Jakeel began to simply do what Rebecca asked, his talk, and the talk of the whole group, became less on-task and less mathematical: After Excerpt 4, the next 249 utterances (almost one third of all talk during the lesson) contained only two mathematizing utterances, both by Rebecca. It required the teacher's intervention (in Turn 597), and in particular her request for a mathematical explanation from Jakeel, to bring the group back to the mathematics of the task. Thus, not only did AOS utterances limit opportunities to mathematize in the short term (in the subsequent utterances), these utterances also had long-term effects, altering the focus of the entire group in undesirable ways.

While the majority of the AOS talk was on-task talk, the students also talked about people's activities unrelated to the task. These activities included topics related to bodies (e.g. farting, eating, crossing eyes), who said what, and events outside of the classroom. Unlike the on-task AOS talk, this talk involved more descriptions of physical activity and many fewer commands or directions about physical activity. This talk also produced more responses from the addressees than on-task AOS talk. Frequently, these responses were disagreements with what was said (e.g. "You was in the game." "No I wasn't" "Yeah you was." "No I wasn't"), but sometimes the responses were an explanation or request for more information. For example, Daren announced that another student ate all of his cookies. Jakeel wanted to know who this student was and then proceeded to announce this information to other students, involving others in the conversation. Daren's initial statement about eating his cookies developed into a total of 11 off-task AOS utterances. This event demonstrates how off-task AOS talk tended to beget more off-task talk, adding to the total off-task time.

Some of this off-task AOS talk occurred as students worked on the tasks. For example, all three students debated a recent soccer game as they cut out the squares in figures $\mathrm{J}$ and $\mathrm{K}$. The students also tended to engage in off-task AOS talk as they waited for the teacher to respond to a question or check their finished work. In these instances, the off-task AOS work, while not contributing to mathematizing also did not seem to detract from it as the students were already waiting or working.

However, there were three instances in which off-task AOS talk seemed to be used to purposefully derail on-task talk. These instances were all initiated by Jakeel in response to an on-task AOS statement by Rebecca. For example, toward the beginning of the task, Rebecca wrote her answer and then told Daren and Jakeel to write her answer.

Excerpt 6. Rebecca directing and Jakeel resisting.

\begin{tabular}{lll}
\hline 174 & Rebecca & Daren and Dakeel this is what I wrote. \\
175 & Jakeel & Dakeel? \\
176 & Rebecca & I said Jakeel \\
177 & Jakeel & You said Dakeel. \\
178 & Rebecca & Whatever. H and I cover the same amount. \\
& & Figure I has one square and two half squares \\
& & that equals two squares. Write that. Write that \\
& & People write this. \\
179 & Daren & Dakeel
\end{tabular}

$\begin{array}{ll} & \text { On AOS } \\ & \text { Off AOS } \\ & \text { Off AOS } \\ \text { Daren smiles. } & \text { Off AOS } \\ \text { Rebecca reads from her paper. She puts her } & \text { On AOS } \\ \text { paper between Daren and Jakeel. } & \end{array}$

Daren looks at Jakeel.

Off I 


\begin{tabular}{llll}
180 & Jakeel & Daren & Jakeel talks to Daren \\
181 & Rebecca & Jakeel! & Rebecca is emphatic. \\
182 & Jakeel & Rebecca! & Jakeel says this in imitation of Rebecca's tone. \\
& & He then laughs. \\
\hline
\end{tabular}

As in Excerpts 2 and 4 above, Rebecca's AOS talk in Turns 174 and 178 directed Jakeel and Daren to write what she wrote. Jakeel responded to these directives with off-task AOS responses (Turns 175, 177, and 182) that critiqued Rebecca's talk and seemed to serve the dual purposes of undermining Rebecca's claim to status and establishing Jakeel's right to participate. Thus while Jakeel's retorts moved the group's talk off-task, they allowed him to maintain his social and academic independence from Rebecca and continued his engagement with the mathematical task. In spite of Rebecca's repeated attempts to direct Jakeel, he persisted in his pursuing his own ideas until the moment captured in Excerpt 4. As these examples illustrate, the story of off-task AOS talk is complicated. In many cases, it seemed to detract from possible mathematizing by diverting the students' attention from the task. However, in some instances, when off-task talk established student's right to participate, it permitted the possibility for mathematical talk, opening the door for mathematical learning.

\subsubsection{Identifying}

Talk about people clearly dominated in this lesson. As described above, almost half of talk in this lesson was devoted to what people do. Another $19.8 \%$ ( $0.7 \%$ on-task and $19.1 \%$ off-task, 148 utterances total) focused on directly identifying people by talking about who they were or their features. The students, or at least Rebecca, noticed the volume of identifying talk - or, in Rebecca's words, "All this talking about people!" (Turn 490).

The following conversation demonstrates this identifying talk. After some time working on the task, Jakeel asked Daren where Nerissa was.

Excerpt 7. Talk Identifying Jakeel.

\begin{tabular}{llll}
\hline 286 & Jakeel & Where Nerissa? & to Daren \\
287 & Daren & Who Nerissa? You Nerissa. You took her spot. I'm here. & Off AOS \\
288 & Jakeel & I ain't Nerissa. & Daren talks first to Jakeel and then to Rebecca. \\
289 & Daren & Yes you is. Isn't he Nerissa? & Off I \\
290 & Jakeel & I'm not a girl. & Off I \\
291 & Daren & You took her spot. Just call you Nerissa. & Off I \\
\hline
\end{tabular}

Daren began this round of identifying by turning Jakeel's straightforward inquiry about Nerissa (Turn 286) into a statement that purposefully misidentified Jakeel as Nerisa (Turn 287). This taunting misnomer required Jakeel to respond and attempt to reidentify himself, resulting in several turns of identifying talk. This example demonstrates both the nature of the identifying (or misidentifying) and the ways in which initial identifying talk resulted in a cascade of identifying turns.

Many of the identifying utterances were teasing misidentifications resembling the example above. However, there were many other identifying instances in which the students used more offensive and purposefully naughty words, such as retarded, stupid, a pejorative word referring to gay people, and other expletives referring to individuals who regularly engage in lewd activities. Across the lesson, there were only two instances in which individuals identified others in complementary or neutral ways. The first was a comment from Daren, "[Jakeel] got some good jokes". The second was initiated by the teacher asking which student was the materials manager (responsible for obtaining materials for the group). Aside from these moments, the identifying seemed to be purposefully inaccurate, perhaps as an invitation to engage in conversation (in contrast to the subjectifying-doing talk which focused more on inciting a physical response from the addressee). And the invitations were successful: The instigator frequently received at least one identifying utterance in return.

The main provocateur in this identifying talk was Jakeel. He was involved as the author or an addressee in all but 10 of the 148 identifying utterances. The following excerpt offers an example of Jakeel's preoccupation with the ways in which he felt his peers identified him. It occurred early in the lesson as Jakeel worked on comparing figures $\mathrm{H}$ and $\mathrm{I}$.

Excerpt 8. Jakeel as a Black brother.

\begin{tabular}{llll}
\hline 230 & Teacher & Okay. So what is the area of this figure H? & On M \\
231 & Jakeel & I don't know. I haven't cutted it out yet. & On AOS \\
232 & Teacher & Okay & Teacher leaves. Daren and Rebecca giggle. \\
233 & Jakeel & What? & Jakeel leans over to look at Rebecca. \\
234 & Daren & You're just like I haven't cutted it out yet. & Rebecca waits. \\
$235 \mathrm{a}$ & Jakeel & I ain't stupid Rebecca. & Off AOS \\
$235 \mathrm{~b}$ & Jakeel & I can see you smile. & Off I \\
$235 \mathrm{c}$ & Jakeel & What's so funny? (1 s pause) & Off AOS \\
$235 \mathrm{~d}$ & Jakeel & What? A Black brother can't talk? & Off AOS \\
\hline
\end{tabular}

In Turn 235a, Jakeel directly identified himself to Rebecca as "not stupid". With his statement, "What? A Black brother can't talk?" (Turn 235d) Jakeel articulated his understanding that Rebecca was identifying him as Black. For Jakeel, Rebecca's 
giggles about his words (Turn 232) carried a message that tied his race to whether he could talk. It seems important to note that Jakeel addressed himself to Rebecca and not Daren, even though Daren was just as active as Rebecca in laughing at Jakeel's statement. Daren even explicitly described what was problematic in Jakeel's talk (Turn 234). Singling out Rebecca, who was White, seemed to send the additional message that Rebecca was drawing upon her race to limit his talk.

Connections between race and talk arose in another type of identifying interaction, something Daren called "blaze" or "Black guy jokes" (see Turn 515 in Excerpt 10 below). When the students blazed, they made negative identifying utterances about members of each others' families ("At least my momma don't got a skillet head like your momma") or negative identifying utterances that described exaggerated physical attributes of each other ("Your head is a big as Saturn"). These utterances almost always provoked a counter attack that negatively identified the original author ("Your head bigger than the sun"). For example,

Excerpt 9. Daren and Jakeel blaze.

\begin{tabular}{lll}
\hline 297 & Daren & Why you talking with your buck tooth gap teeth? \\
298 & Jakeel & I wouldn't be talking with your gap. \\
299 & Daren & Your gap is bigger than mine. \\
300 & Jakeel & Your face is bigger than mine. \\
301 & Daren & You got the biggest teeth I've ever seen. \\
302 & Jakeel & Your momma's got the biggest teeth I've ever seen. \\
303 & Daren & Same to you \\
304 & Jakeel & Same to you \\
305 & Daren & Same to you \\
\hline
\end{tabular}

This "blazing" was similar to other identifying talk (such as that in Excerpt 7) in that it involved negative misidentifications that invited a response from the addressee. However, it differed from the other identifying talk in that it was specifically focused on creative exaggeration (e.g. "Your momma ear is bigger than your own momma's planet" Turn 543) rather than on academic taunts or naughty words.

It seems that for Daren and Jakeel, blazing was important because it directed attention to the issue of who (not only which person, but which race of people) could talk. For example, here is an excerpt that occurred in the middle of several turns of blazing:

Excerpt 10. Daren and Jakeel blaze again.

\begin{tabular}{|c|c|c|c|c|}
\hline 512 & Daren & Your family got a big egg head & & Off B \\
\hline 513 & Jakeel & Your family's (a ho) & Jakeel looks around before he talks & Off $\mathrm{C}$ \\
\hline 514 & Daren & Ohhh & & NC \\
\hline 515 & Daren & Black guy jokes & & Off I \\
\hline 516 & Jakeel & Black guy jokes, big jokes. Okay & The teacher comes by and leaves. & Off I \\
\hline
\end{tabular}

In this excerpt, Daren and then Jakeel label their blazing as "Black guy jokes" (Turns 515 and 516). While the word "blaze" has not yet been documented in the literature on Black language, the game of trading insulting hyperboles is clearly connected to Black oral tradition (Smitherman, 2000). Through this game, Daren and Jakeel both identified as Black and staked a racial claim to their right to talk, a claim which paralleled Jakeel's challenge in Excerpt 8 above ("A Black brother can't talk?" Turn 235d).

While Daren and Jakeel easily engaged in the jesting identifying or blazing, Rebecca was less skilled parrying and returning identifying insults. For example, consider this round of blazing between Rebecca and Jakeel:

Excerpt 11. Rebecca and Jakeel blaze.

\begin{tabular}{lll}
\hline 449 & Jakeel & Your momma \\
450 & Rebecca & Your momma \\
451 & Jakeel & Your momma \\
452 & Rebecca & Your ugly momma \\
453 & Jakeel & Your ugly daddy \\
454 & Rebecca & Ahhhh. My daddy ain't ugly \\
456 & Jakeel & Your ugly generation \\
457 & Rebecca & I don't have a ugly generation \\
458 & Jakeel & Yo momma do \\
459 & Rebecca & Off B B \\
& & Off B \\
\end{tabular}

Rebecca's retort in Turn 452 was consistent with the rules of blazing: She parried with a comment about Jakeel's momma that added insulting detail to the identification and challenged him to reply with a better insult. However, her subsequent responses (Turns 454, 457, and 459) were defensive and were denials of Jakeel's statements rather than new insulting elaborations and seemed to terminate the blazing game.

In a later moment, Rebecca began to blaze with Daren. 
Excerpt 12. Rebecca and Daren blaze.

\begin{tabular}{llll}
\hline 570 & Rebecca & You got yellow teeth & \\
571 & Daren & Why you talking? You got yellow tooth, too & Off B \\
572 & Rebecca & Liar (Lie) (Unintelligible) & Off B \\
573 & Daren & (Unintelligible)You been chewing on a yellow kleenex & Off I \\
574 & Rebecca & Not as yellow as yours & Off B \\
575 & Rebecca & You, Jakeel. You shut up & Off B \\
576 & Daren & You can't be saying & Off AOS \\
578 & Rebecca & [Yes I can & Off AOS \\
579 & Daren & [You can't be saying & Off AOS \\
580 & Daren & You can't be saying it (Unintelligible) & Daren's talk overlaps with Rebecca's in Turn 578. \\
581 & Rebecca & Yes I can. I said it like you (Unintelligible) & Off AOS \\
\hline
\end{tabular}

Rebecca's blazing (Turns 570 and 574) was not as creative as Daren's (Turn 573). In addition, with her "You shut up" (Turn 575), Rebecca shifted from the game of inventive insults to a much less interesting debate about who could talk. Again, rather than extending the game of insults, Rebecca's identifying talk, like her subjectifying talk, discouraged the talk of her peers. In contrast, for Jakeel and, to a lesser extent, Daren, some of the identifying talk in this lesson seemed important not only as a means of crafting a space for talk and interaction, but also as a tool for connecting talk and the right to talk with race.

\subsubsection{None of the above}

Another category of student discourse was talk that was neither about mathematics nor about people, but instead ranged over a variety of other topics including materials, songs, and bodily functions (5.2\% on-task and 10.6\% off-task, 119 utterances total). For example, students talked about whether their answers needed to be the same. This talk was on-task, but it did not focus on people or mathematical objects. (This talk occurred at the beginning of the lesson, so the students did not yet have answers. Instead, they were establishing the norm that they needed to agree on their answers.) Most of the ontask talk that we categorized as none-of-the-above (NOTA) was about the materials for the task (13 utterances). The students talked about whether they had enough, where the materials were, and which materials belonged to which student.

The off-task talk in this category included singing or talk about songs ( 9 utterances), nonsense words (11 utterances), the camera ( 7 utterances), and the materials ( 8 utterances). Off-task talk about materials included moments when Jakeel animated the glue sticks and zoomed them around the table:

Excerpt 13. Off-task talk.

\begin{tabular}{llll}
\hline 615 & Daren & My glue is not an action figure. & Jakeel flips his glue and then takes his glue over to attack Daren's glue. \\
616 & Jakeel & Uh oh! Pop up. Pop up. Back (flip) & $\begin{array}{l}\text { Off } \mathrm{N} \\
\text { Heel maks lays it flat and then flips it over. }\end{array}$ \\
\hline
\end{tabular}

As this example demonstrates, the off-task NOTA talk seemed to contribute very little to the progress of the mathematical work. In contrast, the on-task NOTA talk seemed important for managing the work of the task. For example, the students talked about what was written on the task card (Turn 667) and the materials available for the task (e.g. glue and scissors, Turns 139-145). While this talk did not directly advance the mathematics of the lesson, it seemed to be a necessary component of the group's work as it facilitated understanding of the task and coordination of available resources.

\subsection{Mathematizing}

\subsubsection{What was learned - how did the discourse change during the lesson?}

The final category of utterances, and the smallest, is talk involving mathematics. Out of 749 total utterances, only 79 (10.6\%) focused on mathematical objects, accounting for just $4: 51 \mathrm{~min}$ of the $54: 40 \mathrm{~min}$ (8.9\% of the time) spent working in the small group. Given this limited mathematizing, it is appropriate to wonder whether the students were able to learn anything.

Surprisingly, these few utterances were enough for Jakeel (but not Rebecca or Daren) to exhibit desirable changes in his mathematical discourse. The excerpt below demonstrates Jakeel's initial mathematical discourse. This interaction occurred 13 min into the small group work time. The teacher was asking Jakeel to justify what the children, or at least Rebecca, have already written in their notebooks: that Figures H and I (see Fig. 3) "cover the same amount" (Rebecca, 178).

Excerpt 14. Jakeel's initial mathematical discourse.

\begin{tabular}{cclc}
\hline 193 & Rebecca & $\begin{array}{l}\text { We're telling the answer first and then we're going to prove it. } \\
\text { I'm proving it right now. See it says H and I cover the same amount }\end{array}$ & On AOS \\
194 & Teacher & $\begin{array}{l}\text { Jakeel. What do you think? How can you prove this? What could } \\
\text { you do? What materials do you have that could prove this? }\end{array}$ & She picks up a paper with Figures H and I.
\end{tabular}




$\begin{array}{lll}195 & \text { Jakeel } & \text { H and I. They both have squares. } \\ 196 & \text { Teacher } & \text { Okay but are they the same? } \\ 197 & \text { Jakeel } & \text { Yes } \\ 198 & \text { Teacher } & \text { Do they cover the same } \\ 199 & \text { Rebecca } & \text { I know } \\ 200 & \text { Teacher } & \text { I mean Jakeel. How } \\ 201 & \text { Jakeel } & \text { Cause it's a square } \\ 202 & \text { Rebecca } & \text { Cut this out } \\ & & \\ 203 & \text { Teacher } & \text { But this isn't a square } \\ 204 & \text { Jakeel } & \text { No, so that's why it won't cover the same. }\end{array}$

He points at the figures on the paper the teacher is holding.

The teacher puts the paper down.

Daren and Rebecca raise their hands

Jakeel points at the full square in Figure I. She takes a paper with $H$ and $I$ on it and picks up scissors.

She points at the two triangles in Figure I.
On M

On M

On M

On $\mathrm{M}$

On AOS

On AOS

On M

On AOS

On M

On M

This excerpt shows that Jakeel had no routine for tackling the type of question the children were supposed to answer: "[W]hich of the rugs covers more area or if they cover the same amount[?]" (see Fig. 2). He recognized that the solution somehow involved activity with squares, which he mentioned twice (Turns 195 and 201). However, the way the squares were supposed to be considered was not clear to him, in particular he did not seem aware of the need to quantify the squares. He also had difficulty determining the meaning of the words "the same" as uttered by both Rebecca and the teacher (Turns 193 and 198). His assertion that both Figures I and H "have squares" (Turn 195) revealed Jakeel's belief that the property of containing identical squares could count as the sufficient reason for sameness. When the teacher responded with the question "Okay but are they the same?" (Turn 196), Jakeel gave an affirmative answer, possibly interpreting the teacher's query as regarding the squares themselves. The teacher's subsequent acts of repeating the question about sameness (see Turn 198), and of alerting Jakeel to the triangles in Figure I (Turn 203) forced him to abandon his previous interpretation of "the same". While responding in negative in Turn 204, he evidently relied on the fact that squares and triangles, which cannot count as "the same", should be considered when sameness is being tested. To summarize, at this point in time, Jakeel had no routine for tasks featuring the word area or for establishing the area of a figure or any type of area comparison.

By the end of the lesson the situation was different. Jakeel's discourse had changed: He now could respond to questions about areas of figures, and he did it by counting the identical squares into which the figures could be decomposed. The following excerpt occurred $53 \mathrm{~min}$ into the small group work time. Jakeel had finished work on the second pair of figures (J and $\mathrm{K}$ ). The teacher asked Jakeel to show her the area of figure J (see Fig. 4).

Excerpt 15. Jakeel's final mathematical discourse.

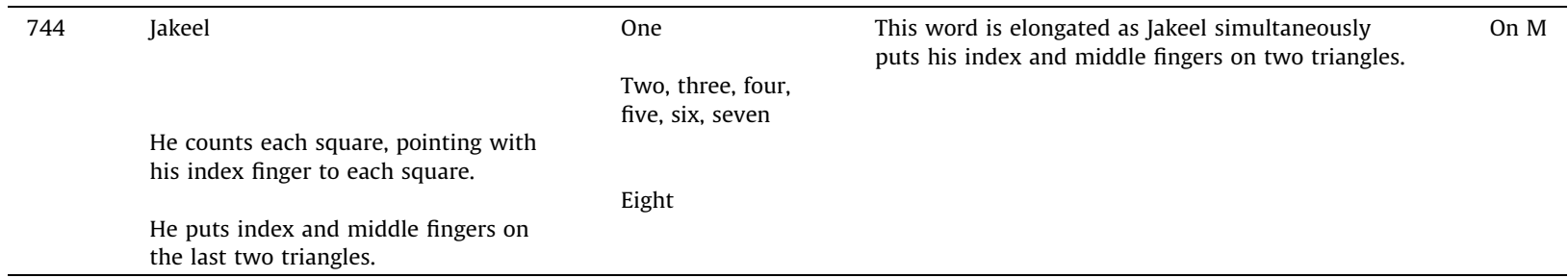

Note that Jakeel had developed his own method for counting the triangular spaces: He simultaneously pointed at two triangles, while uttering just one number and thus enumerating these shapes as if they constituted a square. These alterations in Jakeel's discourse reflect Jakeel's mathematical learning during this lesson.

Jakeel's performance during a subsequent lesson provides evidence that this change in his discourse was durable, and was thus a case of genuine learning. This later lesson directed students to "Find the area of each right triangle" pictured in Fig. 6. While working on the isosceles triangle in the middle of Fig. 6, Jakeel was able to explain to another student how the "two [triangles in the larger triangle] make a square" and how, as a consequence, the larger triangle had two squares. Jakeel now had words to describe what was only a pointing action in the previous lesson. He also understood that questions about the area of figures should be answered by counting the smaller spaces and other squares in the figure.
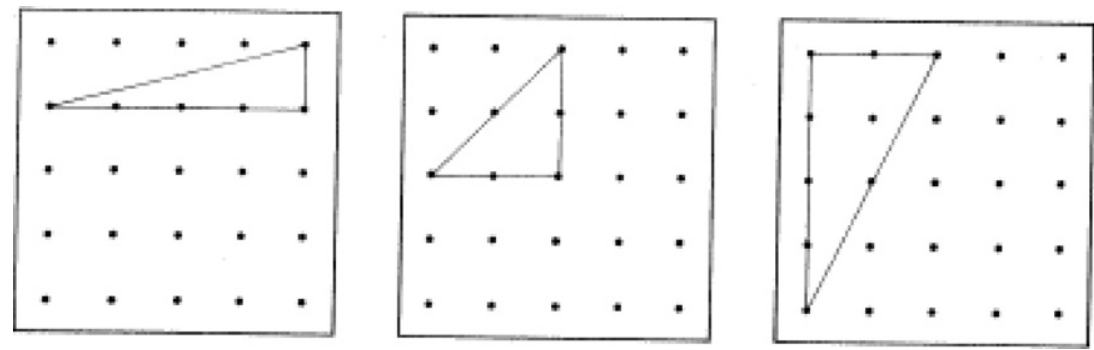

Fig. 6. Examples of figures from a later lesson. 
As noted earlier, one remarkable feature of Jakeel's mathematical learning is that it occurred with so little mathematizing talk: He was able to alter his discourse when just $10.6 \%$ of the total utterances were mathematical. Of these 79 mathematizing utterances, Jakeel uttered 31. (Rebecca uttered 17. Daren uttered 10 and the teacher uttered 21.) From this perspective, Jakeel was much more involved in the mathematics of this lesson than his two partners.

This difference in mathematizing may reflect more upon his partners' initial mathematical discourses and the opportunities for them to learn in this lesson than on their desire to mathematize or their distractions into other kinds of interactions. During a previous lesson, Rebecca and Daren had worked together on another problem involving the area of triangular figures. During that lesson, Daren had realized (and shared with Rebecca) that when a triangular figure was overlaid with a square grid (similar to I and J in Figs. 3 and 4), the small triangles created by the grid were half squares and could be counted such that one pair was equivalent to one square. As a consequence (and in contrast to Jakeel), Rebecca and Daren (as illustrated in the excerpts below) already had routines with which to solve this task. We see this in Turn 170 when Daren explains his solution Figures $\mathrm{H}$ and I to Jakeel:

Excerpt 16. Daren explains to Jakeel.

\begin{tabular}{llll}
\hline 70 & Daren & $\begin{array}{l}\text { You see the one square and that's got two. You put these together. } \\
\text { That's two squares. So they cover the same area. }\end{array}$ & Daren is pointing at Jakeel's paper.
\end{tabular}

Rebecca presented her routine explicitly as she read her answer to Daren and Jakeel. Notice that in this excerpt, she was not explaining her ideas, but telling Jakeel and Daren what to write:

Excerpt 17. Rebecca directs Jakeel and Daren (also part of Excerpt 2 above).

\begin{tabular}{llll}
\hline $178 \quad$ Rebecca & $\begin{array}{l}\text { Whatever. H and I cover the same amount. Figure I has } \\
\text { one square and two half squares that equals two squares. } \\
\text { Write that. Write that. People write this. }\end{array}$ & $\begin{array}{l}\text { Rebecca reads from her paper. She puts her paper } \\
\text { between Daren and Jakeel. }\end{array}$ \\
\hline
\end{tabular}

Because Rebecca and Daren already possessed routines which allowed them to easily respond to the request to compare the two figures, the task presented very little, if any opportunity for them to learn a new mathematical discourse. One can therefore say that in their case, no substantial learning, that is, no change in their discourses occurred during this lesson.

As an aside, let us remark that in the above report on the students' learning we considered only one type of discursive change: the change in routines. There are, however, other aspects of discourse and other types of change that could be discussed. Considering the fact that the overall aim of this learning unit was for the children to start constructing for themselves the mathematical object called area, it is useful to have another look at our data and ask where the children stand, at this point in time, with respect to their word use.

The first thing that strikes the eye is the scarcity of the actual appearances of the all important keyword area. A simple count through the transcript shows that during this lesson, the word was explicitly pronounced only 7 times, 5 of which were by the teacher. The two uses made by students seem to be instances of quoting ready made phrases. In one case, Rebecca rephrased the directions she had read in the task card, in the other case, Daren formulated an answer to the first task, using the expression "cover area," which was a part of the question (see Excerpt 19, Turn 170 below). The claim we wish to make is that at this stage in the development of the discourse, the word area does not yet signify any mathematical object and for some students, its role, when pronounced by others, is that of a signpost: Its appearance in a task of a given form orients the students toward a particular solution routine.

The support for this interpretation comes from the fact that the students seemed to be struggling while trying to formulate the final solution of the tasks they were dealing with. In the first of these tasks, involving Figures $\mathrm{H}$ and $\mathrm{I}$, the most natural thing to say would be "the figures cover the same area" or, better still, "the figures have the same area." This verbalization, however, escaped the students, showing that they had little idea about this "thing" that was supposed to be "the same"2. This can be seen in all the cases in which they felt obliged to pronounce the words the same to formulate their answers. In the sentences they produced, the words the same, rather than being followed by the word area, were either left without any complement, as in "H and I cover the same" ( 8 cases out of the total of their 20 uses of the words "the same") or were associated with such "replacements" as amount or amount of floor (11 out of 19 uses). Particularly informative in this respect was Rebecca's struggle for words while she dictated the solution of the first task to Jakeel (see Excerpt 2 in section 4.1.1): "They... H and I cover the same amount of floor. I mean just cover the same amount. $\mathrm{H}$ and I cover the same amount of floor. No, just they cover the same amount. Same. Amount." ${ }^{3}$

\footnotetext{
${ }^{2}$ The ability to use the words "the same" in conjunction with a mathematical signifier ("the same area", "the same number", "the same function") in a situation where two different things are being compared has been argued by Sfard and Lavie (2005) to be one of the most powerful indicators of the fact that the user has constructed the signified mathematical object.

${ }^{3}$ Note that the wording of task, as can be seen in Fig. 2, was rather confusing with respect to the question of what objects were compared: it spoke about rugs, area, and amount as objects of comparison, and floor was also implied as what is covered by rugs.
} 
To sum up, at this point in time one cannot yet speak about the students' discourse on area. Rather, there is a collection of unconsolidated routines for solving some well-defined tasks featuring the word area. The use of word as a "signpost," characteristic of this stage in discourse development, has been described in Sfard (2008) as "routine-driven". It seems that little has happened during this lesson to advance students beyond this stage.

\subsubsection{How and why did Jakeel's learning occur?}

As we have noted before, Jakeel was able to learn in spite of the limited mathematizing present in this lesson. Jakeel's peers, whose mathematical talk was more appropriate and sophisticated than his own, were a potential learning support for him. Both Rebecca and Daren could evaluate Jakeel's mathematical talk and model more desirable talk. However, while there were times in which both Daren and Rebecca interacted with Jakeel in ways that encouraged him to mathematize and to change his mathematical discourse, most of the peer interactions with Jakeel (and primarily Rebecca's, as was elaborated in Section 4.1.1 above) provided directions on what to do to and how to finish the task and served primarily to limit Jakeel's talk rather than to encourage him to develop a more desirable mathematical discourse.

In contrast to Rebecca and Daren's interactions with Jakeel, the teacher's interactions, although infrequent (the teacher talked 69 times) were effective in engaging Jakeel (and his peers) in mathematizing talk that eventually led to a change in his talk. Of the 42 teacher interactions with Jakeel, 19 invoked a mathematizing response from Jakeel. These teacher turns were all requests (in the form of questions or commands) for Jakeel to explain his activity or thinking. For example, this interaction occurred 39 min into the lesson. Jakeel was determining the area of Figures J and K (see Fig. 4). The teacher asked Jakeel for the area of figure $\mathrm{J}$.

Excerpt 18. The teacher engages Jakeel in mathematizing.

\begin{tabular}{|c|c|c|c|c|}
\hline 601 & Teacher & What is [the area of Figure J]? Tell me what it is. & & On M \\
\hline 602 & Jakeel & Eight $^{4}$ & & On $\mathrm{M}$ \\
\hline 603 & Teacher & How is that eight? I can't tell that's eight. & & On $\mathrm{M}$ \\
\hline 604 & Jakeel & $\begin{array}{l}\text { Because one, two, three, four, five, six, seven, } \\
\text { eight, nine, t-. Hold on }\end{array}$ & $\begin{array}{l}\text { Jakeel points to the spaces in Figure J as } \\
\text { he counts. He points once at each space } \\
\text { with the pinky of his right hand. }\end{array}$ & On $\mathrm{M}$ \\
\hline 605 & Rebecca & Can I tell him? & The teacher leaves. & On AOS \\
\hline 606 & Jakeel & It's & & On M \\
\hline 607 & Rebecca & Okay, Jakeel. You see those little triangles. & She points to Figure J on Jakeel's paper. & On M \\
\hline 608 & Jakeel & Yes & & On $\mathrm{M}$ \\
\hline 609 & Rebecca & $\begin{array}{l}\text { Those are half a squares. Look and if you put these } \\
\text { together, those equal a square and so it's eight, } \\
\text { it's eight and eight. }\end{array}$ & $\begin{array}{l}\text { She points back and forth between } \\
\text { Figures J and } K \text {. }\end{array}$ & On $\mathrm{M}$ \\
\hline 610 & Jakeel & Oh. one $=$ & $\begin{array}{l}\text { Jakeel is pointing to spaces in Figure J. } \\
\text { Rebecca interrupts him. }\end{array}$ & On M \\
\hline 611 & Rebecca & $\begin{array}{l}\text { So write that if you put the two half squares together } \\
\text { it makes a square. If you put two half squares together, } \\
\text { it makes a square. Write that on your paper. Write that. } \\
\text { Then you're done Jakeel. }\end{array}$ & $\begin{array}{l}\text { Jakeel points at the spaces in Figure J. } \\
\text { His motions suggest that he is silently } \\
\text { counting. It looks like he points at squares } \\
\text { with one finger and at triangles with two fingers. }\end{array}$ & On AOS \\
\hline 612 & Jakeel & Oh, yeah! & & On $\mathrm{M}$ \\
\hline
\end{tabular}

In Turn 602 Jakeel seemed to be saying that the area of Figure J was eight and yet, when he attempted to demonstrate how he knew this, he could not (Turn 604). His "hold on" (Turn 604) demonstrates that he was aware that his counting was not yielding the right outcome. When Rebecca offered to "tell him" how to solve the task, he listened to her mathematical talk (Turns 607 to 609). He then began to recount the area of the figure (Turn 611), and, as was demonstrated in Excerpt 15, he was eventually able to correctly count the spaces in figure J. Jakeel's discourse changed after he realized, as he responded to the question from the teacher, that his system for determining area (count every space in the figure as one, see Turn 604) did not give him the right answer.

This excerpt requires one side comment. It illustrates the findings of Section 4.1.1 (Action-Oriented Subjectifying: Talk about doing) and also epitomizes the sequence of talk throughout the lesson. Rebecca moved from mathematizing talk (Turn 609) to telling Jakeel what to write (Turn 611). This progression also occurred in the larger lesson with more mathematizing at the beginning of the lesson, followed by action-oriented subjectifying (and eventually much off task talk). It is important to note that in this excerpt, Jakeel attended to Rebecca's talk when she was mathematizing, but when she attempted to tell him what to write (Turn 611), Jakeel ignored her and was instead absorbed in counting spaces and determining area. His focus on Rebecca's mathematizing and not on her action-oriented subjectifying seemed to advance his learning.

This moment of learning seemed to depend upon a sequence of mathematizing interactions across a variety of people. The teacher first provided the opportunity to learn by asking Jakeel to mathematize. Then, Rebecca, through her mathematizing

\footnotetext{
4 Jakeel's "Eight" seems to have come from an interaction that occurred 10 min prior to this moment. The students had started work on Figures J and K. Rebecca looked at the two figures and, while Jakeel watched, counted the number of squares in each. She stated, "We have to figure out which covers the most. This [figure K] covers eight. This [figure J] covers one, two, three, four, five, six, seven, eight. They cover the same. All right. All right. All right. All right?" (Turns 391-392).
} 
with Jakeel, provided a model discourse that Jakeel could use. These interactions suggest that mathematizing begets other mathematizing in ways that can lead to mathematical learning.

One final point remains about Jakeel's mathematizing. It seemed important to Jakeel to respond to his peers' mathematizing with mathematizing of his own. This was evident in Excerpt 18 above in which Jakeel reacted to Rebecca's explanation of area by counting out area on his own. The following excerpt, which occurred just as the group was beginning to work on the first task (involving figures $\mathrm{H}$ and I), also illustrates this point. Daren had solved the task and Jakeel asked Daren to explain his solution:

Excerpt 19. Jakeel's mathematizing with peers.

\begin{tabular}{|c|c|c|c|c|}
\hline 165 & Daren & This is half. If we put this together that's two squares. & He points to the triangles in Figure I. & On M \\
\hline 166 & Jakeel & That's a obtuse. & Jakeel points at Figure I. & On $\mathrm{M}$ \\
\hline 167 & Daren & We don't care about that! We not doing that. Look, look. & Jakeel has picked up his own copy of Figures $H$ and $I$. & On $\mathrm{M}$ \\
\hline 168 & Daren & You see how that & Daren points at the paper Jakeel is holding. & On $\mathrm{M}$ \\
\hline 169 & Jakeel & This is I & He points at his paper. & On $\mathrm{M}$ \\
\hline 170 & Daren & $\begin{array}{l}\text { You see the one square and that's got two. You put these } \\
\text { together. That's two squares. So they cover the same area. }\end{array}$ & $\begin{array}{l}\text { Daren is pointing at Jakeel's paper. It is not clear } \\
\text { what he is pointing at. After this statement, } \\
\text { Daren turns to his paper. }\end{array}$ & On $\mathrm{M}$ \\
\hline 171 & Jakeel & Can you say that again? & & On AOS \\
\hline
\end{tabular}

In Turns 166 and 169, Jakeel inserted himself in Daren's mathematizing. While Jakeel's statement in Turn 166 was mathematically inaccurate, ${ }^{5}$ this statement and the next demonstrated that he wanted to contribute to and participate in the mathematizing. In addition, when Daren completed his explanation (Turn 170), Jakeel asked him to repeat it, inviting Daren to extend their mathematizing conversation.

\section{Discussion}

\subsection{Lessons about mathematical talk}

It would be difficult to offer this classroom episode as an argument for small group learning. The group interactions provided very few moments of mathematizing ( $10.6 \%$ of utterances) and thus very few opportunities to learn. However, the lesson does offer insights into several aspects of student interactions and is thus instructive for researchers and teachers. First, it seems important to acknowledge that learning occurred in spite of the scarcity of mathematizing. This finding hints that mathematical learning, rather than correlating with the quantity of mathematical talk, might be more closely tied to other factors such as questioning or realizing contradictions. This finding is consistent with Cobb's argument (in Sfard, Nesher, Streefland, Cobb, \& Mason, 1998) that what is said seems to be more important than how much is said.

Whereas this first recommendation suggests the need for additional examination of kinds of mathematizing talk and their connection to learning, we also conjecture that more mathematical talk, especially of the kind of mathematical explanations that seemed to have spurred Jakeel's progress, might also improve mathematical learning. In Section 4.2.2, we provide some evidence that when Jakeel's peers mathematized, he mathematized in return. In addition, Jakeel's eventual learning followed an instance of Rebecca's mathematizing. It is thus reasonable to assume that if Rebecca had engaged in more mathematizing and less action-oriented subjectifying, Jakeel's resistance to Rebecca would be less pronounced and his identifying talk less prominent, and he might have had more opportunities to mathematize and learn. It is in this sense that we see increasing the quantity of mathematizing, not just its quality, as potentially beneficial for mathematical learning.

This lesson also offers reasons why it may be challenging to increase the quality or quantity of student mathematical talk. Even when students were on task, most of their talk was not mathematical. Instead, much of the talk focused on getting the group (and especially Jakeel) successfully through the assigned task. In spite of the limitations on learning caused by this subjectifying talk, many administrators, teachers, and even some researchers would, at a surface level, see this talk as positive and not problematic because it was thanks to this organizational talk that the students were accomplishing their work. Current definitions of on- and off-task time do not distinguish between time spent mathematizing and time spent subjectifying. For example, Chiu (2004) defined on-task as "engaging in student behaviors conducive to problem solving, including suggesting or executing solution proposals, encouraging others to work on the problem, listening to solution proposals, and discussing solutions" (p. 373). While this definition describes many desirable behaviors, it does not preclude Rebecca's directions to Jakeel (which could be construed as suggesting solution proposals and as encouraging others to work on the problem). In order to increase the time students spend mathematizing, we need to more clearly differentiate mathematizing from other kinds of talk, and in particular other kinds of on-task talk. Also, we need to consider how mathematical tasks might be engineered and how student groups might be structured to increase the quality and perhaps quantity of mathematizing talk and minimize other kinds of talk that weaken participants' engagement in mathematizing.

\footnotetext{
${ }^{5}$ The triangle was a right triangle, but Nerissa, when partnered with Jakeel in an earlier lesson, labeled all right triangles as obtuse. Jakeel clearly learned from Nerissa in this earlier lesson.
} 
Some might argue that there is a potential risk in asking minority students and others seen as less academically competent to engage in more mathematizing: If these students are not already comfortable with mathematical talk, they might be further excluded by efforts to increase the quality or quantity of this talk. While we acknowledge this concern, we feel it is important to not to exempt these students from mathematizing. An elaboration of our definition and intentions might help explain our position. This definition is not limited to the talk about mathematical objects that is academically desirable. The term "mathematizing" includes any talk that focuses on mathematical objects. Drawing from a funds-of-knowledge perspective (Moll, Amanti, Neff, \& Gonzalez, 1992), we assume that while some students might be more skilled at generating academically desirable mathematical talk, all students are able to mathematize, or talk about mathematical objects. Furthermore, we suggest that many students who, like Jakeel, are perceived as less competent and are shut out from group interactions, would be able to participate and contribute to mathematical conversations provided they are given proper opportunities. Indeed, Jakeel not only proved to be capable of mathematizing, he was very eager to participate in mathematical conversations and had the most mathematizing turns of the three students. Thus, rather than see our recommendation to increase mathematical talk as perhaps excluding those who cannot, we would like to suggest that it would be a mistake to perpetuate the differences in academic mathematizing by excluding students from this form of talk. Indeed, we believe that the ability to participate is not a matter of any "inborn" determinant, but it is rather a function of opportunity to practice. This is true even though, admittedly, different learners may need different amount of practice to arrive at an academically satisfactory competence. Our task as teachers is to craft situations that provide students with appropriate opportunities for participation, while also strengthening their engagement in mathematical talk.

\subsection{Lessons about identifying talk}

Our findings regarding the group's (and in particular Jakeel's) considerable engagement in identifying suggests that researchers might focus more on the social, affective, and mathematical work accomplished by identifying talk and the ways in which identifying talk is intertwined with the development of mathematical discourse. Many investigations of identifying during mathematics lessons examine how students identify as mathematical learners (e.g. Boaler \& Greeno, 2000; Cobb, Gresalfi, \& Hodge, 2009; Martin, 2005) but do not consider other, mathematics-unrelated types of identifying or how any kind of identifying talk influences other interactions occurring during a lesson. For example, in this group, most of the identifying in this lesson seemed to primarily serve the purpose of provoking a response from the addressee by specifically misidentifying the addressee or his/her family. In this way, the identifying encouraged back and forth interactions in which all interlocutors were invited to contribute to the conversation. This is in contrast to Rebecca's action-oriented subjectifying which tended to limit interactions. While the identifying conversation was not itself conducive to learning, Jakeel's enthusiastic participation parallels his engagement in mathematizing: He seemed to prefer interactions (mathematical and nonmathematical), in which all interlocutors, including himself, were invited to talk. If we knew more about how students use identifying talk (including how Jakeel used identifying to provoke interaction), we might be able to encourage identifying talk that supports, rather than detracts from, mathematical learning.

The students' identifying talk also communicated Jakeel's (and to a lesser extent, Daren's) attention to racialized and possibly gendered aspects of talk. Thus, when Jakeel's task-related talk was criticized (as when Rebecca and Daren giggled at his talk in Turns 231 and 232), he invoked race and gender to claim that he had the right to talk. When Rebecca limited his mathematical talk, he turned to blazing, identifying talk that both he and Daren labeled "Black guy talk". Jakeel's focus on blazing and identifying resulted in portions of the lesson in which the White girl was successful (most of the mathematizing and on-task work) and parts in which the Black boys were successful. Unfortunately, these different kinds of talk are not equally valued in society. Rebecca's failure to succeed at blazing had no institutional or academic consequences for her while Jakeel's limited opportunities to mathematize could mean reduced academic success eventually followed by reduced economic opportunities. Fortunately, the intervention of the teacher provided Jakeel a second opportunity to mathematize and benefit from the lesson.

Jakeel's perception of his experiences in this lesson, as we see it, is consistent with and adds to Martin's (2000, 2006) descriptions of mathematics as a racialized experience. Martin (2000) conducted classroom observations of Black junior high school students and interviewed students, parents and community members. He found that issues of race permeated their stories of learning math and that Black students who were successful found ways of mitigating negative messages and overcoming obstacles. In Martin's findings, the parents were explicit about ways in which race affected their opportunities to learn. However, students, both in interviews and in Martin's classroom observations, did not seem to make as many direct connections to race. Thus Jakeel's activity adds to Martin's work by providing an additional in-class example of how one student experienced his mathematical learning as racialized and how the student called attention to the ways in which race was involved in his talk and participation.

Also, Jakeel's case adds nuance to Martin's findings about successful and unsuccessful students. Jakeel was successful when the teacher intervened. This intervention not only brought the students (and in particular Jakeel) back to the mathematical task, but it also framed Jakeel as capable of mathematizing and completing the task (Wood, 2008) which contrasted with Rebecca's framing of Jakeel as someone who should follow her directions. These classroom events demonstrate both how successful students may limit the mathematical learning of other students and how teachers may serve an important role in helping lower status youth be successful. 


\subsection{Lessons about student interactions and their impact on learning}

The contrast between Jakeel's invitations to talk and Rebecca's redirection from talk suggests the need to be careful about positioning students as peer teachers and pupils of those peer teachers. A frequent perspective in classrooms is that students who know more should teach students who know less and that the talk of those who know more, both the quantity and content, is unproblematic. However, for the most part, Rebecca's talk was, in fact, harmful to Jakeel's learning. By focusing Jakeel's time and effort on meaningless replication of her words and her work, she distracted him from mathematical talk and limited his mathematical talk and time available to engage in mathematical talk. This finding resonates with findings by Webb (1991) that showed that in some instances receiving "help" from peers is negatively related to achievement. One lesson to take from this is that we cannot merely put students together and expect them to learn from each other. Instead, in order for students to gain from peer teaching, we must specifically teach students how to help one another.

Even when students are taught effective teaching behaviors, however, there is the potential for peer teaching to be problematic from an equity perspective. The work of Fuchs et al. (1997) demonstrated that successful peer helping interactions increased the learning of both the peer teacher and the pupil. While these learning gains are positive, one problematic aspect is that the peer teaching seems to maintain the achievement gap between the high achievers (the peer teachers) and the low achievers (their pupils): While the scores of both groups of students increased, the difference between their scores was maintained. If we hope to narrow this achievement gap, we must examine how peer teaching might perpetuate this problem. The interactions of Rebecca and Jakeel offer some insights into this issue.

Peer teaching inherently positions some students (the peer teachers) as more capable than others (their pupils). This positioning may provide the "teachers" with more opportunities to talk and try out their ideas, limiting the opportunities for their "pupils" to do the same. It may also play a purely affective role, providing peer teachers with more confidence in their ability to solve mathematical tasks. The labels of teacher and pupil may also narrowly construe what counts as an academic strength. Rebecca had the opportunity to teach Jakeel because she knew the answer. Yet, if we assigned a higher academic value to Jakeel's social skills, we might better appreciate how Jakeel's interest in talk could support him and others in learning. While Jakeel lacked the mathematical discourse to serve as an effective model for others, he consistently drew others into his conversation, including (as in Excerpt 19) mathematical conversations. If the teacher had recognized and publically valued Jakeel's interest in and ability to engage in mathematical talk, she might have been able to position him as having something to contribute to the group. Over time, as Jakeel's discourse became more mathematical, his inclination to invite others to talk could mean that he would be more effective in engaging others in mathematizing and learning than Rebecca. While this sequence of events is highly conjectural, it suggests a means by which the roles of peer teacher and pupil might be replaced by interactions that reflect less of a power difference, which might ultimately provide the former pupils with more opportunities to mathematize and realize the same achievement gains as the teachers.

The difference between Jakeel's preference for interactions and Rebecca's preference for directing activity points to a clash of discourses that occupied much of this lesson. Rebecca, Jakeel, and Daren had not yet established interactive norms and spent much of the lesson negotiating how to proceed as a group. Rebecca effectively established herself as in charge of mathematical activity while Jakeel took over off-task interactions. Interestingly, Daren became a border crosser, at times following Rebecca's directions and at other times engaging in Jakeel's identifying. The time spent on negotiations and final resolution of interactive routines suggest that teachers who want to encourage student interaction will need to attend to, allow for, and prepare to guide the exchanges that will ultimately become the template for students' interactive routines.

Finally, the differences between Jakeel's and Rebecca's interactional preferences lend insights into the continuing research on learning through group work. Many researchers (e.g. Cohen, 1994a; Slavin, 1980) argue that when done right, group work is an effective learning strategy. Other researchers have found that group work can reduce the achievement gap as underachieving students find opportunities to participate and thus to learn (Boaler \& Staples, 2008; Vaughan, 2002; Webb \& Farivar, 1994). However, Cohen (1994a) noted that the success of underachieving students depended upon their ability to participate in the work of the group. This participation was not guaranteed merely by the structure of the group and was easily undermined by high status individuals in the group. This case offers more details about what kind of participation is most desirable and what kinds of talk the high status student might use to limit the quantity and quality of participation of the low-status students. If teachers were alert to students' use of activity-oriented subjectifying to limit mathematizing interactions and if they could establish norms that promoted, rather than limited, productive mathematical discourse, they might begin to address some of the inequitable participation that can undermine groupwork.

\section{Conclusion}

Our investigation of small-group classroom interactions revealed that students tend to be preoccupied with talk about what others should do (action-oriented subjectifying) and who others are (identifying). These two kinds of talk can compete not only with each other, but also with the kind of talk that might lead to learning: mathematizing talk. In this case, these two kinds of talk became mutually reinforcing. Rebecca increasingly focused on Jakeel's final product (rather than on his mathematical talk) and Jakeel increasingly focused on crafting space for interaction (which, because the opportunity for mathematical talk was foreclosed, became nonmathematical in nature). These phenomena become particularly conspicuous when contrasted with the kinds of talk present in student-teacher interactions which tended to draw students toward more mathematical talk. 
On the surface, these findings suggest that we should do away with small group interactions and their myriad of undesirable kinds of talk in favor of whole class discussions in which the teacher could moderate, model, and encourage more productive mathematical talk. However, whole class discussions are not a panacea for all that ails in mathematics education: Small group discussions, when they are successful, provide many more opportunities for students to engage in (and potentially learn from) productive mathematical talk.

Rather than serve as evidence against small group interactions, we suggest that our findings provide teachers with tools for diagnosing and hopefully mitigating unproductive student talk. As teachers notice the kinds and purposes of student talk, they may be able to design tasks and rehearse norms that specifically address this problematic talk and encourage more desirable talk. In particular, we suggest that students who seem the most off task (like Jakeel), might be very interested in mathematical talk, but might be blocked from such talk by the efforts of more successful students. As teachers gain tools for facilitating mathematical talk from all students, more students might become successful mathematical learners.

\section{Appendix A. Supplementary data}

Supplementary data associated with this article can be found, in the online version, at doi:10.1016/j.ijer.2011.12.008.

\section{References}

Andriessen, J., Baker, M., \& van der Puil, C. (2011). Socio-cognitive tension in collaborative working relations. In S. Ludvigsen, A. Lund, I. Rasmussen, \& R. Saljo (Eds.), Learning across sites: New tools, infrastructures and practices (pp. 222-242). London: Routledge.

Boaler, J., \& Greeno, J. (2000). Identity, agency, and knowing in mathematics worlds. In J. Boaler (Ed.), Multiple perspectives on mathematics teaching and learning (pp. 171-200). Westport: Ablex Publishers.

Boaler, J., \& Staples, M. (2008). Creating mathematical futures through an equitable teaching approach: The case of Railside School. Teachers College Record, 110(3), 608-645.

Chiu, M. M. (2004). Adapting teacher interventions to student needs during cooperative learning: How to improve student problem solving and time on-task. American Educational Research Journal, 41(2), 365-399.

Cobb, P., Gresalfi, M., \& Hodge, L. L. (2009). An interpretive scheme for analyzing identities that students develop in mathematics classrooms. Journal for Research in Mathematics Education, 40(1), 40-68.

Cohen, E. G. (1994a). Designing groupwork: Strategies for the heterogeneous classroom (2nd ed.). New York: Teachers College Press.

Cohen, E. G. (1994b). Restructuring the classroom: Conditions for productive small groups. Review of Educational Research, 64, 1-35.

Fuchs, L. S., Fuchs, D., Hamlett, C. L., Phillips, N. B., Karns, K., \& Dutka, S. (1997). Enhancing students' helping behavior during peer-mediated instruction with conceptual mathematical explanations. The Elementary School Journal, 97(3), 223-249.

Lemke, J. L. (1990). Talking science: Language, learning, and values. Norwood, NJ: Ablex.

Martin, D. B. (2000). Mathematics success and failure among African-American youth: The roles of sociohistorical context, community forces, school influence. and individual agency, Mahwah, NJ: Lawrence Erlbaum Associates Inc.

Martin, D. B. (2005). Race, identity, and mathematics literacy: African American counternarratives. Michigan State University College of Education.

Martin, D. B. (2006). Mathematics learning and participation as racialized forms of experience: African American parents speak on the struggle for mathematics literacy. Mathematical Thinking and Learning, 8(3), 197-229.

Miles, M. B., \& Huberman, A. M. (1994). Qualitative data analysis: An expanded sourcebook. Thousand Oaks, CA: Sage Publications.

Moll, L. C., Amanti, C., Neff, D., \& Gonzalez, N. (1992). Funds of knowledge for teaching: Using a qualitative approach to connect homes and classrooms. Theory into Practice, 31(2), 132-141.

Sfard, A. (2008). Thinking as communicating: Human development, the growth of discourses, and mathematizing. Cambridge, UK: Cambridge University Press.

Sfard, A., \& Lavie, I. (2005). Why cannot children see as the same what grown-ups cannot see as different? - Early numerical thinking revisited. Cognition and Instruction, 23(2), 237-309.

Sfard, A., Nesher, P., Streefland, L., Cobb, P., \& Mason, J. (1998). Learning mathematics through conversation: Is it as good as they say? For the Learning of Mathematics, 18(1), 41-51.

Slavin, R. E. (1980). Cooperative learning. Review of Educational Research, 50, 315-342.

Smitherman, G. (2000). Talkin that talk: Language, culture, and education in African America. Routledge: New York.

Thornborrow, J. (2003). The organization of primary school children's on-task and off-task talk in a small group setting. Research on Language E' Social Interaction, $36(1), 7-32$.

Vaughan, W. (2002). Effects of cooperative learning on achievement and attitude among students of color. The Journal of Educational Research, 95(6), 359-364.

Webb, N. M. (1991). Task-related verbal interaction and mathematics learning in small groups. Journal for Research in Mathematics Education, 22(5), 366-389.

Webb, N. M., \& Farivar, S. (1994). Promoting helping behavior in cooperative small groups in middle school mathematics. American Educational Research Journal, $31(2), 369-395$.

Webb, N. M., \& Mastergeorge, A. (2003). Promoting effective helping behavior in peer-directed groups. International Journal of Educational Research, $39,73-97$. Wortham, S. (2006). Learningidentity: The joint emergence of social identification and academic learning. New York, NY: Cambridge University Press.

Wood, M. B. (2008). Mathematizing, identifying, and autonomous learning: Fourth grade students engage mathematics (Doctoral dissertation). Retrieved from ProQuest Dissertations and Theses Database (AAT 3332041). 